\title{
GEOMETRIA NA EDUCAÇÃO INFANTIL: DA MANIPULAÇÃO EMPIRISTA AO CONCRETO PIAGETIANO
}

\section{Geometry in child education: from empiricist manipulation to the theory of Jean Piaget}

\author{
Simone de Souza ${ }^{1}$. Valdeni Soliani Franco ${ }^{2}$
}

Resumo: Refletir sobre os conhecimentos de geometria do professor de educação infantil e as concepções epistemológicas que fundamentam suas condutas pedagógicas foi o objetivo de nossa pesquisa. A análise dos discursos indicou boa vontade das professoras para o trabalho geométrico, entretanto o desconhecimento da geometria enquanto teoria e a enraizada concepção epistemológica empirista, reportaram à ideia de que este conhecimento está nos objetos, bastando sua manipulação para que haja aprendizagem. Assim, caberia às crianças, por meio de estímulos e da organização dos materiais manipuláveis pelos docentes, a descoberta das formas geométricas presentes no mundo que as rodeia. Buscamos, na epistemologia genética de Jean Piaget, as bases sólidas para contribuições à reflexão e atuação de professores.

Palavras-chave: Educação infantil. Ensino de geometria. Análise do discurso. Aprendizagem. Piaget, Jean.

\begin{abstract}
The aim of this study is to reflect on child education teachers' geometry knowledge and the epistemological conception that characterizes their educational behavior. The discourses analysis shows us that good teachers' willingly undertake geometry study. However the non-acquaintance theory and the rooted epistemological empiricist conception indicate that the knowledge is in the objects and the manipulation of these objects is enough to achieve learning. It was possible to confirm the empiricist conception's superiority through educational practice where the children discover the geometrical forms in the world by the stimuli and material organized by the teachers. We used Jean Piaget's genetic epistemology as basis for reflection by teachers on their performance.
\end{abstract}

Keywords: Children education. Geometry teaching. Discourse analysis. Learning. Piaget, Jean.

\footnotetext{
${ }^{1}$ Universidade Estadual de Maringá (UEM). Rua Vereador Joaquim Pereira de Castro, 547, Vila Santo Antonio. Maringá, PR, Brasil. 87.030-170. simoneejordao@hotmail.com

${ }^{2}$ Departamento de Matemática, Centro de Ciências Exatas, UEM. Maringá, PR, Brasil.
} 


\section{Introdução}

Este artigo é parte de nossa pesquisa de mestrado em que investigamos a conduta metodológica de seis professoras de educação infantil analisando qual a concepção epistemológica que deu suporte ao ensino da geometria proporcionado por elas.

Longe de encontrarmos respostas definitivas, nossa pesquisa fornece novas perguntas impulsionadas pelos discursos coletados em entrevista semiestruturada e relato escrito, o que permitiu a realização de um ensaio interpretativo com a intenção de auxiliar a tomada de consciência, pelas docentes, da concepção epistemológica, que sustenta suas práticas metodológicas.

O relato das professoras acerca do "como" e o "porquê" do trabalho com geometria, indica que o ensino da matemática continua reduzido às noções numéricas, o que torna a geometria um apêndice da prática escolar. Este apêndice agrava-se quando as professoras apontam a supremacia da alfabetização do ler e escrever sobre a alfabetização matemática. Unindo-se a esses aspectos, ainda há a defasagem da formação acadêmica relatada por elas, que, ao nosso entender, não envolve uma proposta de ensino de matemática de qualidade, no qual a teoria alia-se à prática num todo coerente, auxiliando na promoção de um trabalho significativo para o desenvolvimento do conhecimento geométrico infantil.

Neste contexto, quando o trabalho geométrico é realizado, vêm à tona as lacunas teóricas e práticas, que, por sua vez, nos conduziram ao problema de nossa pesquisa: o que revela o discurso do(a) professor(a) de educação infantil referente a sua concepção epistemológica e a sua conduta metodológica diante da geometria?

Identificamos que a conduta epistemológica das professoras entrevistadas fundamentase no empirismo, no qual as noções geométricas encontram suas fontes nos materiais manipuláveis. Diante da postura empirista, apresentamos a teoria construtivista como possibilidade de superação do ensino estático e refém da manipulação de materiais, entendendo que as crianças são ativas e construtoras de seu próprio desenvolvimento, sendo o professor aquele que instiga e orienta as descobertas infantis.

\section{Referencial teórico}

É comum identificarmos, no discurso docente, falas progressistas contrárias às práticas arcaicas. Qual a razão disto? Segundo Becker (2001, p. 31), o modelo pedagógico conservador não é passível de críticas epistemológicas durante a formação inicial e continuada dos professores, o que impede as mudanças. Suas pesquisas denunciaram que "[...] a crítica está ausente e o quanto seu primitivismo conserva o professor prisioneiro de epistemologias do senso comum, tornando-o incapaz de tomar consciência das amarras que aprisionam o seu fazer e o seu pensar".

Entendemos que o aprofundamento de estudos sob a perspectiva epistemológica permite identificar os fundamentos que sustentam as práticas educativas e que a epistemologia genética de Jean Piaget é uma das fontes teóricas que possibilitam a análise crítica das concepções que sustentam o fazer(-se) docente. 
$\mathrm{Na}$ busca de compreender o conhecimento científico, é importante encontrar respostas às questões relativas "[...] ao papel e às atividades do sujeito do conhecimento, ou seja, à compreensão dos processos do conhecimento científico, em função de seu desenvolvimento ou de sua própria formação" (FÁVERO, 2005, p. 96). Em outras palavras, para analisar como o conhecimento progride, nada melhor que estudar este processo na criança.

Desta forma, "[...] a focalização nos fatos normativos que revelam as estruturas lógicas da inteligência, o forte papel da ação no centro de um construtivismo que reúne o sujeito e o objeto" (BIDEAUD, 2002, p. 20) na perspectiva piagetiana, nos dão os elementos necessários para compreendermos o desenvolvimento do sujeito.

Entretanto há duas correntes de pensamento que tentam explicar este desenvolvimento por outras vias que não a da relação dialética entre sujeito e objeto, abordada pelo construtivismo.

A primeira delas é o Inatismo, que entende o conhecimento como pré-formado. Essa doutrina acredita que o sujeito nasce com estruturas prontas e que são atualizadas durante o desenvolvimento. Esta forma de explicação prioriza a hereditariedade, concebendo a aprendizagem como um fator maturacional. Desta forma, há um determinismo biológico do qual não se pode escapar (FELIPE, 1998), cabendo à psicologia e à educação "[...] medir o quociente intelectual e predizer até onde podemos ir, até onde seremos capazes de aprender" (MACEDO, 2002, p. 120). Neste contexto, a aprendizagem subordina-se ao desenvolvimento, cabendo, ao professor, selecionar materiais adequados às necessidades e possibilidades das crianças - mensuradas mediante testes de Quociente de Inteligência (Q.I.) e outras provas psicológicas e pedagógicas.

O fato de se considerarem as condições biológicas para o desenvolvimento da inteligência humana não é um engano; porém não é suficiente para determinar a natureza da mesma. Ou seja, a bagagem hereditária e sua maturação não agem isoladamente. As conquistas cognitivas sofrem o efeito das experiências, ou seja, da ação nos objetos.

A segunda corrente que tenta explicar o desenvolvimento do sujeito, o Empirismo, focaliza as experiências numa perspectiva unitária cujo foco está no ambiente. Na medida em que o sujeito entra em contato com este ambiente, acumula experiências e torna-se humano. Aqui, o desenvolvimento é subordinado à aprendizagem, visto que a criança, ao ser considerada "tábua rasa", somente progride pela ação de determinantes externos (BECKER, 2003).

A nosso entender, na educação, o determinismo externo é representado pelo professor, que escolhe os recursos, os conteúdos e a metodologia utilizada em sala de aula, isto é, define os meios a seguir para atingir suas metas. Às crianças cabe um papel de submissão e passividade, capazes de aprender somente o que os professores ensinam.

Constatado o aprisionamento docente às condutas inatista e empirista em pesquisas no campo educacional - dentre elas, a nossa - como colaborar para que velhas amarras abram espaço para a teoria construtivista e, com ela, para a emergência de novas possibilidades práticas? Segundo Piaget (1975 apud BECKER, 2003, p. 14), o desafio está no professor assumir a função de "[...] inventar situações experimentais para facilitar a invenção de seu aluno". Desta forma, as condutas docentes devem ser refletidas em uma nova concepção de aprendizagem, a construtivista, que permite ao professor "aprender" com o seu aluno (BECKER, 2001). 
A função do professor que aprende com os alunos adquire legitimidade e une o ensinar e o aprender num processo dinâmico de organização de ações significativas.

Becker (2003, p. 14) salienta que está, na ação do sujeito, a fonte de aprendizagem, ou seja, "[...] o indivíduo aprende por força das ações que ele mesmo pratica: ações que buscam êxito e ações que, a partir do êxito obtido, buscam a verdade ao apropriar-se das ações que obtiveram êxito".

Este movimento da ação executada, refletida e recriada pelo sujeito é o ponto-chave da teoria construtivista, o que torna fundamental o acesso consciente dos docentes às implicações desta concepção para a aprendizagem infantil. Chamamos de acesso consciente ao contato mais profundo com a teoria construtivista, contrariamente a uma visão superficial da mesma por tornar-se uma moda entre os docentes.

Por meio desse contato, torna-se evidente que a teoria construtivista de Jean Piaget não foi elaborada com intenções pedagógicas, e que este primeiro equívoco desencadeou uma série de mal-entendidos, sintetizados por Matui (1995, p. 33), ao se referir aos esclarecimentos de Emília Ferreiro. Dentre estes mal-entendidos, elencamos:

a) A ideia de construção foi relacionada a dois polos distintos, que são os conceitos de aprendizagem e o de maturação. Esta aprendizagem está fortemente ligada ao empirismo e a situações metodológicas de estímulo-resposta. Para a "maturação", práticas espontaneístas tomaram o lugar daquelas rigorosamente diretivas.

b) $\mathrm{O}$ construtivismo não tem o mesmo significado de método ativo. $\mathrm{O}$ fato de propor muitas atividades para as crianças e a busca de receitas por parte do professor é permanecer numa visão superficial do construtivismo.

c) O objetivo da teoria construtivista não é atingir a criatividade. Abrir espaço para as ideias espontâneas, curiosas e extraordinárias das crianças não significa, por si só, uma postura construtivista.

d) O processo de construção ocorre somente de início. Alguns professores permitem que algumas coisas sejam construídas como introdução ao associacionismo, que virá depois, como se o ato de construir fosse apenas uma estimulação para o conhecimento.

Há um grande número de docentes - e não somente as seis entrevistadas para nosso estudo - que não têm clara a teoria que está por trás de sua prática, que esta perpetua um único modelo de educação.

Desta forma, na tentativa de amenizar esta miopia epistemológica, retomaremos alguns postulados construtivistas.

O núcleo da epistemologia construtivista situa-se na ação do sujeito sobre o objeto, sendo ambos transformados durante a relação que estabelecem. Para compreendermos a profundidade da ação na terminologia piagetiana, recorremos aos esclarecimentos de Kamii e Devries (1985), que atribuem ao termo ação dois significados.

Com referência às ações manipulativas sobre os objetos, 
[...] ação significa fazer alguma coisa ao (ou com o) objeto; tal como empurrá-lo, puxá-lo ou colocá-lo na água. O segundo significado de ação é mais difícil de entender porque a criança pode agir sobre o objeto sem mesmo tocá-lo. (KAMII; DEVRIES, 1985, p. 35)

O segundo significado entende a ação como uma atividade mental que se origina na manipulação física e, gradualmente, internaliza-se. As autoras citadas exemplificam esta diferenciação entre ação manipulativa - ligada à percepção através dos sentidos - e ação internalizada.

Quando a criança olha para seis cubos azuis e dois amarelos e pensa neles como 'azuis e amarelos', ela está se concentrando em suas propriedades específicas por um lado e, por outro lado, está também ativando uma rede total de relações. Ou seja, para pensar nos cubos como cubos, ela deve distinguir suas semelhanças e diferenças em relação a todos os outros objetos. (KAMII; DEVRIES, 1985, p. 35)

Desta maneira, o "pensar nos cubos como cubos" reporta a ação internalizada na qual a criança mentalmente estabelece relações que lhe permitem reconhecer um cubo para além de suas propriedades visíveis.

Assim, a ação supõe a relação entre sujeito e objeto, na qual o sujeito "[...] dinâmico, versátil, plástico" (BECKER, 2003, p. 27) estabelece contato com o objeto, que, por sua vez, envolve aspectos do meio físico e social.

O que podemos perceber é que o objeto da epistemologia construtivista é muito mais abrangente do que o senso comum estabelece, ou seja, objeto não é somente o percebido pelos sentidos, mas, também, tudo o que é criado pelo sujeito, seja na relação com o manipulável, seja nas relações estabelecidas entre abstrações.

\section{Objetivos}

Relacionar a fundamentação teórica baseada em Jean Piaget e autores colaboradores com a prática escolar atual do ensino de geometria na educação infantil, e identificar como os professores concebem o ensino da geometria na educação infantil e o trabalho que proporcionam a seus alunos e alunas.

\section{Metodologia}

Adotamos, em nosso trabalho, a pesquisa qualitativa, por compreendermos que esta concepção de investigação "[...] engloba a ideia do subjetivo, passível de expor sensações e opiniões” (BICUDO, 2004, p. 104), o que geralmente não é focalizado no nível quantitativo.

Utilizamos a entrevista semiestruturada para identificar a concepção geométrica e a conduta metodológica de seis docentes atuantes em educação infantil, em turmas de crianças 
entre cinco e seis anos de idade. O registro das informações foi facilitado pelo uso de gravador de voz e pela posterior transcrição, seguida da análise do que foi dito.

Pelo caráter investigativo de nosso estudo, definimos que, entre as seis docentes participantes, três seriam atuantes de instituição pública e três da rede particular de ensino. Utilizamos, como critério de escolha das escolas e das docentes participantes, a resposta positiva ao nosso convite.

Primeiramente, foi apresentado, à direção e coordenação pedagógica das escolas visitadas, o projeto de pesquisa, para que pudéssemos ter acesso às professoras e convidá-las a participarem. Após algumas resistências, encontramos professoras voluntárias dispostas a conceder a entrevista gravada e a redigir a atividade descritiva, com a garantia do anonimato e o conhecimento da finalidade das informações a nós fornecidas.

Foram feitas leituras e releituras do material coletado, a partir das quais passamos a “[...] identificar e selecionar episódios, depoimentos ou partes de texto que têm relação explícita ou implícita com a questão investigativa" (FIORENTINI, 2006, p. 143).

Assim, a leitura e a interpretação das informações coletadas entre as professoras enquadraram-se na opção de se utilizar como ferramenta alguns elementos de Análise de Discurso, o que implica aceitar o desafio de "[...] realizar leituras críticas e reflexivas que não reduzam o discurso a análises de aspectos puramente linguísticos nem o dissolvam num trabalho histórico sobre a ideologia" (BRANDÃO, 2004, p. 103).

Para nos referirmos às professoras, atribuímos, para as que atuam na rede pública de ensino, os numerais 1, 2 e 3; e, para aquelas que atuam em escolas particulares, as letras A, B e C. Desta forma, citaremos: de acordo com a professora C... Assim relata a professora $2 \ldots$

\section{Desenvolvimento}

Entendemos que a manipulação assume dois aspectos diferenciados, demonstrados durante as entrevistas realizadas com as professoras participantes de nossa pesquisa.

O primeiro aspecto envolve o manipulável enquanto percepções sensoriais dos objetos, sendo estes os tributários do conhecimento. O segundo refere-se à manipulação discursiva e didática, em que há o falseamento de condutas arcaicas através de uma roupagem verbal que pode ou não iludir o leitor.

O fato de tentar escamotear, no discurso, condutas epistemológicas contrárias à construtivista, supõe o que acreditamos ser a busca da modernidade, de assumir uma linguagem progressista na aparência. Um exemplo disto está no uso dos termos criar e criatividade, como gestores de uma prática inovadora, mas que, tratados nos moldes empiristas, promovem o espontaneísmo.

De acordo com o relato da professora 1, o trabalho geométrico é importante para a educação infantil, porém ele não é feito com profundidade.

“[...] a gente faz a identificação das figuras, mas não só, por exemplo, claro que a gente fala como que é o quadrado. O que é um quadrado? Quem sabe? Tem quatro partes iguais? E o retângulo? Tem duas partes iguais e duas diferentes e tal [...]. Aprender a reconhecer as figuras 
geométricas, porque as figuras geométricas estão no nosso mundo, nosso cantinho, em tudo o que a gente vai fazer". E ainda comparando este trabalho com outros conteúdos matemáticos, diz: "eles se interessam bastante quando são figuras geométricas, chama bastante a atenção deles. Quando é trabalhar com figuras, porque eles manuseiam, é uma coisa concreta, material concreto". (professora 1)

É evidente a supervalorização do material manipulável, atribuindo a ele, também, o fator da motivação infantil, o que é diferente de reconhecer a necessidade do suporte concreto à aprendizagem - não somente da geometria - para o estádio de desenvolvimento em que crianças de cinco a seis anos de idade se encontram.

Segundo Piaget (2006, p. 78),

[...] a experiência que incide sobre os objetos pode manifestar duas formas, sendo uma a lógico-matemática, que extrai os conhecimentos não apenas dos próprios objetos, mas também das ações como tais que modificam esses objetos. Esquece-se, por fim, de que a experiência física, por sua vez, onde o conhecimento é abstraído dos objetos, consiste em agir sobre estes para transformá-los, para dissociar e fazer variar os fatores etc, e não para deles extrair, simplesmente, uma cópia figurativa.

Parece-nos claro que o relato da professora 1, "claro que a gente fala como é o quadrado, e, aprender a reconhecer as figuras geométricas", confirma a conduta epistemológica empirista, na qual o foco está no treinamento visual e verbal das crianças. Visual, no sentido de que através da união do observado e do tateio das formas - e não das figuras - as crianças são treinadas a identificar as figuras elementares. Para o aspecto verbal, tanto professora quanto alunos utilizam a linguagem para reforçar o conhecimento extraído do material, conferindo a ele as nomenclaturas científicas.

Como assevera Piaget (2006, p. 48)

Desde que se trata da fala ou do ensino verbal, parte-se do postulado implícito de que tal transmissão educativa fornece à criança os instrumentos próprios da assimilação, ao mesmo tempo em que os conhecimentos a assimilar, esquecendo que esses instrumentos só podem ser adquiridos pela atividade interna e que toda assimilação é uma reestruturação ou uma reinvenção.

A professora 2, referindo-se ao que é explorado enquanto geometria e a importância desta para a educação infantil, relata: "geometria, a gente observa o mundo, o espaço onde a gente está e a gente vê tudo nele, é, são formas geométricas. Então dá para você explorar até o chão que você está pisando. Tudo enfim, dá para trabalhar a geometria, não é?”.

Desta maneira, o conhecimento geométrico está no mundo visível, a ser descoberto, e que a docente explora, conduzindo as crianças à identificação de propriedades que estão 
postas externamente. Em outras palavras, o mundo está pronto geometricamente e às crianças basta apreendê-lo.

No entanto, o importante é reconhecer as relações que estabelecemos com o mundo e que permitem a construção do conhecimento geométrico. E, ainda, observar quais relações as crianças estão estabelecendo e demonstrando - pela linguagem, pelo desenho, pelas construções - para, a partir daquelas, promover o intercâmbio das primeiras noções geométricas com o conhecimento geométrico cientificamente organizado.

A concepção de que o conhecimento está no mundo exterior e que, para adquiri-lo, é necessário copiar seus modelos, é claramente demonstrado pela professora 3: "Para ensinar a geometria com as crianças de educação infantil, partimos sempre de exemplos e modelos extraídos do seu ambiente, ou seja, da realidade (concreto), isso também acontece com outros conteúdos como: português e matemática".

Em outro momento, a docente acrescenta que, através de joguinhos de formas, as crianças trabalham e "é dali que a gente vai tirando as ideias e vai vendo qual o interesse maior deles e elaborando os outros conteúdos".

Observa-se que a "elaboração" do conteúdo está nas mãos do professor, e este acredita que permitir uma suposta origem destes conteúdos ligada às atividades espontâneas infantis provoca a estimulação necessária para afirmar que "eles nessa fase gostam bastante de tudo". E, em função disto, para a geometria, não há dificuldades, visto que, "eles mesmos vão formando, é muito fácil, é tranquilo. Não tem dificuldade nenhuma".

Permanecer apoiada no espontaneísmo infantil garante à docente uma certa tranquilidade e descompromisso com a aprendizagem. O que para Becker (2003, p. 6) "[...] somente um empirista, convicto ou ingênuo, pode acreditar que os métodos didáticos possam ser simples, lineares e totalmente 'pilotados' pelo professor".

A professora $C$ justifica as dificuldades que impedem o trabalho com a geometria, pela via pessoal - do gostar.

\footnotetext{
"Eu acho que tem dificuldade no sentido do professor ter uma formação mais voltada ao conhecer, aprender a gostar. Então depende muito da gente. Porque a gente pode ter um material maravilhoso, se a gente não conseguir a possibilidade de como usar esse material fica o material pelo material. Em outros momentos você pode estar trabalhando numa escola que não te ofereça isso, que você não tem o material, mas que você vai lá, pega uma sucata, um rolinho de papel, você vai trabalhar com o cilindro; pode ter um sentido muito maior. Então eu não vejo que a condição material impeça, mas a formação mesmo". (professora C)
}

O discurso dessa professora também sugere um avanço ao refletir sobre o material disponível, ou não, para o trabalho com a geometria. Contudo, ainda subsiste a concepção de que o material manipulável é o principal, visto que o professor precisa saber como utilizá-lo para não dar margem ao espontâneo e para o docente não perder as rédeas do ensino. Desta maneira, se espera que a formação dê as receitas e instrumentalize a docente. Assim, a condição material não será empecilho, mas contributo. 
A professora A, apesar de trazer em sua fala oscilações entre as concepções inatista e empirista - "essa motivação existe porque nasce com a criança, e, vai muito de como o professor joga para a criança aquela atividade" -, seu discurso representa avanços. Como exemplo, temos o relato a seguir.

\begin{abstract}
"Desde o primeiro dia de aula as crianças são instigadas a observarem o ambiente em que estão inseridas com os objetos (materiais escolares) fazendo suas correspondências, o que é parecido, o que é igual, o que é diferente. Cada criança manipula o seu material tendo oportunidade de perceber suas características (tamanho, forma, cor, peso) e assim poder comparar com o do amigo, com objetos da sala e até com a estrutura física do prédio (por exemplo: esta caixa tem que forma? Com o que mais se parece? Tem mais alguma coisa igual? No que ela é diferente daquela outra? Por quê?)". (professora A)
\end{abstract}

Entendemos que este discurso possui certa fecundidade para a mudança de postura, de empirista para construtivista. Considerar o professor aquele que instiga, que abre oportunidade para comparações e correspondências é um passo para o reconhecimento do papel ativo das crianças.

A partir da abertura de possibilidades, demonstrada pela professora A no decorrer de sua entrevista, acreditamos que o desafio consiste em fortalecer o suporte teórico construtivista, para que aconteça a ruptura definitiva com a concepção empirista e inatista.

Diante do que ficou exposto, faz-se necessário buscar em Piaget o que ele entende por concreto, sendo que, para a concepção empirista, o concreto é o objeto-cópia extraído do ambiente através dos sentidos.

Para o autor,

[...] é preciso, pois, não confundir o concreto com a experiência física, que tira seus conhecimentos dos objetos e não das ações próprias ao sujeito, nem com as apresentações intuitivas no sentido de figurativas, porque estas operações são extraídas das ações e não das configurações perceptivas ou imagéticas. (PIAGET, 2006, p. 54)

Piaget (2006) alerta para a diferença existente entre a ideia de concretude e de experiência. Esta última é necessária, mas não suficiente para o desenvolvimento da inteligência; e apresenta-se sob duas formas: a experiência física e a lógico-matemática. Em suas palavras:

A experiência física consiste em agir sobre os objetos e descobrir as propriedades por abstração, partindo dos próprios objetos. Por exemplo: pesar os objetos e verificar que os mais pesados nem sempre são os maiores. A experiência lógico-matemática (indispensável nos níveis em que a dedução operatória não é ainda possível) consiste, por sua vez, em agir sobre os objetos, mas, no caso, em descobrir as propriedades por abstração a partir, não dos objetos como tais, mas das próprias ações que se exercem sobre esses objetos. (PIAGET, 2006, p. 46)

Poderíamos, então, afirmar que o concreto, numa perspectiva piagetiana, vai além da experiência física, encontrando seu alicerce nas ações do sujeito. Ações que se movimentam 
do manipulável às abstrações, e vice-versa, sem que seja determinado um início e um fim linear.

O processo de abstração, por sua vez, é qualificado pela epistemologia construtivista como abstração empírica e reflexionante.

A abstração empírica consiste em tirar as “[...] informações dos objetos como tais ou das ações do sujeito em suas características materiais, portanto, de modo geral, dos observáveis" (MONTANGERO, 1998, p. 87). Esta maneira de abstrair, na qual o conhecimento é extraído da realidade, possui importância secundária, visto que, para a abstração empírica efetivar-se, é necessária a abstração reflexionante.

A abstração reflexionante incide nas coordenações das ações do sujeito, que age sobre os objetos, o que comporta dois aspectos:

[...] de um lado, um 'reflexionamento', isto é, a projeção (como por um refletor) sobre um patamar superior daquilo que é tirado do patamar inferior (por exemplo, da ação à representação) e, de outro lado, uma 'reflexão' enquanto ato mental de reconstrução e reorganização sobre o patamar superior daquilo que é assim transferido ao inferior. (MONTANGERO, 1998, p. 89)

Para ilustrar este processo, Piaget (1978 apud MONTANGERO, 1998) recorre ao caso de uma criança efetuar o trajeto de casa à escola. Pouco a pouco, a criança pequena guia-se e reconhece o trajeto por referências práticas. Pela abstração reflexionante, este "saber prático" é organizado e projetado ao plano da representação. Ou seja, por esta via, ela é capaz de, pela linguagem ou outros mecanismos de representação, descrever o caminho que a conduz de casa à escola. Desta forma, “[...] a representação é mais rica que o conhecimento do qual é abstraída, porque se trata de uma visão de conjunto simultânea" (MONTANGERO, 1998, p. 91).

Neste contexto, as duas formas de abstração, empírica e reflexionante, são complementares. A primeira retira dos objetos suas qualidades observáveis, enquanto a segunda, apoia-se nas coordenações das ações.

Como exemplo, podemos citar uma criança que, ao manipular dois objetos, identifica-os como leve e pesado. A classificação leve / pesado não está contida em cada objeto, mas, sim, na relação estabelecida entre eles. Assim, não é possível construir a categoria "peso" via abstração empírica pois os objetos em si são apenas suporte às atividades mentais da criança.

A abstração pseudoempírica derruba o empirismo e colabora, em nossa pesquisa, para compreendermos como a criança abstrai.

Entendemos que o modo como as crianças abstraem é desconhecido pelas professoras, confundindo-se o ato de abstrair com os conhecimentos abstratos - aqueles produzidos por ações mentais sobre conceitos, totalmente desvinculados do suporte concreto, as deduções, por exemplo. Desta forma, “[...] ensina-se a Matemática como se se tratasse exclusivamente de verdades acessíveis por meio de uma linguagem abstrata e mesmo daquela linguagem especial que é a dos símbolos operatórios" (PIAGET, 2005, p. 59).

Neste contexto, Piaget (2005) explica o movimento do concreto e abstrato, entendido como complementares, ao esclarecer em que consiste o ensino da matemática sob a concepção construtivista. 
A matemática, porém consiste em primeiro lugar, e acima de tudo, em ações exercidas sobre as coisas, e as próprias operações são também sempre ações, mas bem coordenadas entre si e simplesmente imaginadas, ao invés de serem executadas materialmente. Sem dúvida é indispensável que se chegue à abstração, e isso é mesmo absolutamente natural em todos os terrenos no decorrer do desenvolvimento mental da adolescência; mas a abstração se reduzirá a uma espécie de embuste e de desvio do espírito se não constituir o coroamento de uma série ininterrupta de ações concretas anteriores. A verdadeira causa dos fracassos da educação formal decorre, pois essencialmente do fato de se principiar pela linguagem (acompanhada de desenhos, de ações fictícias ou narradas, etc.) ao invés de o fazer pela ação real e material. (PIAGET, 2005, p. 59)

Desta maneira, Piaget (2005) esclarece que o concreto é fundamental para o desenvolvimento do conhecimento infantil, e que as abstrações decorrentes das manipulações dos objetos ocorrem ligadas às ações sobre eles, em nível elementar, constituindo-se como suporte aos níveis superiores do conhecimento.

A adoção dos fundamentos construtivistas implica atribuir, à matemática e às demais ciências, um dinamismo no qual as condutas docentes recorrem à observação das ações infantis e delas partem para estimular as experiências sobre os objetos. Possibilitando as relações entre eles e promovendo a construção de conhecimentos de maneira autônoma. O que não significa cair no espontaneísmo, mas, sim, assegurar o livre exercício da inteligência pessoal, sem tornar-se individualista.

\section{Conclusões}

Os discursos das professoras confirmaram nossas hipóteses de que o ensino da geometria é reduzido ao estudo das figuras planas elementares. Há, também, desconhecimento da geometria enquanto teoria, e falta de conhecimento quanto ao desenvolvimento infantil e a concepção construtivista.

Em linhas gerais, para a concepção construtivista, as ações das crianças sobre os objetos permitem que relações sejam construídas por elas num patamar superior ao da mera manipulação de materiais. O concreto deixa de ser apenas o que é percebido, como o reduzem os empiristas, para ser o construído internamente através do pensamento. Assim, o papel do professor será o de orientador, de instigador das descobertas infantis e, sobretudo, de organizador de ações significativas, considerando-se os estádios de desenvolvimento cognitivo das crianças.

Acreditamos que o primeiro passo a ser dado pelos professores atuantes na Educação Básica seja conscientizar-se sobre as possibilidades de um ensino diferente de geometria, com respaldo no construtivismo, para, posteriormente, romperem com as práticas arraigadas que reduzem os conceitos geométricos às atividades com as figuras planas, a saber: círculo, quadrado, triângulo e retângulo. É coerente adiar o foco do ensino nos preceitos da geometria 
euclidiana e partir para noções topológicas mais condizentes com o estádio de desenvolvimento em que as crianças se encontram.

Com isto, em médio prazo, a geometria perderá sua posição desprivilegiada diante de outros conteúdos e contribuirá para o estabelecimento de relações entre os objetos, entre os sujeitos, e entre eles e o espaço em que vivemos. Esta relação será diferenciada ao permitir que as crianças construam, também através das ações sobre os materiais manipulativos tidos como apoio, as noções espaciais que serão suportes às abstrações. E deste movimento dinâmico esperamos chegar a reconhecer, na escola, o espaço para o novo, para o criativo, para a curiosidade, para o lúdico.

\section{Referências}

BECKER, F. A origem do conhecimento e aprendizagem escolar. Porto Alegre: Artmed, 2003.

Educação e construção do conhecimento. Porto Alegre: Artmed, 2001.

BICUDO, M. A. V. Pesquisa qualitativa e pesquisa qualitativa segundo a abordagem fenomenológica. In: BORBA, M. C.; ARAÚJO, J. L. (Org.). Pesquisa qualitativa em educação matemática. Belo Horizonte: Autêntica, 2004. p. 99-112.

BIDEAUD, J. Jean Piaget ontem, hoje, amanhã. In: HOUDÉ; O.; MELJAC, C. (Org.). O espírito piagetiano: homenagem internacional a Jean Piaget. Porto Alegre: Artmed, 2002. p. 19-27.

BRANDÃO, H. H. N. Introdução à análise do discurso. Campinas: Editora da Unicamp, 2004.

FÁVERO, M. H. Psicologia e conhecimento: subsídios da psicologia do desenvolvimento para a análise de ensinar e aprender. Brasília: Editora Universidade de Brasília, 2005.

FELIPE, J. Aspectos gerais do desenvolvimento infantil. In: CRAIDY, C. M. (Org.). O educador de todos os dias: convivendo com crianças de 0 a 6 anos. Porto Alegre: Mediação, 1998. p. 7-17.

FIORENTINI, D. Investigação em educação matemática: percursos teóricos e metodológicos. Campinas: Autores Associados, 2006. p. 133-146.

GOULART, I. B. Piaget: experiências básicas para utilização pelo professor. Petrópolis: Vozes, 2003.

KAMII, C.; DEVRIES, R. O conhecimento físico na educação pré-escolar: implicações da teoria de Piaget. Porto Alegre: Artes Médicas, 1985.

962

Ciência \&̊̊ Educação, v. 18, n. 4, p. 951-963, 2012 
Geometria na Educação Infantil: da manipulação ...

MACEDO, L. A questão da inteligência: todos podem aprender? In: OLIVEIRA, M. K.; REGO, T. C.; SOUZA, D. T. R. (Org.). Psicologia, educação e as temáticas da vida contemporânea. São Paulo: Moderna, 2002. p. 117-134.

MATUI, J. Construtivismo: teoria construtivista sócio-histórica aplicada ao ensino. São Paulo: Moderna, 1995.

MONTANGERO, J. Piaget ou a inteligência em evolução. Porto Alegre: Artmed, 1998.

PIAGET, J. Para onde vai a educação? 17. ed. Rio de Janeiro: José Olympio, 2005.

Psicologia e pedagogia. 9. ed. Rio de Janeiro: Forense Universitária, 2006.

PIAGET, J.; INHELDER, B. A representação do espaço na criança. Porto Alegre: Artes Médicas, 1993.

Artigo recebido em 21/11/2011. Aceito em 30/08/12. 